\title{
Violencia conyugal y víctimas de la guerra: la valenciana Beatriz Martí y la troyana Andrómaca de Eurípides
}

\section{Conjugal violence and victims of war: the Valencian Beatriz Martí and the Trojan Andrómaca by Euripides}

\author{
Anastasia Terzopoulou \\ naemdi@otenet.gr \\ Universitat d'Alacant
}

\begin{abstract}
Resumen: En este trabajo se desarrolla el tema de la violencia de la mujer en la Antigua Grecia y en la Corona de Aragón a finales de la Edad Media. Concretamente, los casos que se analizan tienen que ver, por una parte, con la violencia cometida contra la princesa de Troya, Andrómaca, la cual tras el saqueo y la caída de su patria se ha convertido en una cautiva de guerra, en una concubina de la familia que mató a su esposo e hijo; y, por la otra, con la violencia marital de la valenciana Beatriz Martí. Ambas mujeres, a pesar de los siglos que les separan, sufren injusticias y dolor, pero, también cuentan con una persona que les presta su ayuda y protección: en el caso de Andrómaca es Peleo, el abuelo de su actual amo; y, en el caso de Beatriz, la reina María de Aragón.
\end{abstract}

Palabras clave: mujer, violencia, protección, maltrato, defensa

\begin{abstract}
This paper develops the issue of violence against women in Ancient Greece and in the Crown of Aragon in the Late Middle Ages. Specifically, the cases analyzed have to do, on the one hand, with the violence committed against the Princess of Troy, Andromache, who, after the looting and fall of her homeland, has become a war captive, a concubine of the family that killed her husband and son; and, on the other, the case of the marital violence of the Valencian Beatriz Martí. Both women, despite the centuries that separate them, suffer injustices and pain, but they also have a person who helps and protects them: in the case of Andromache it is Peleus, the grandfather of its current owner; and, in the case of Beatriz, Queen Maria of Aragon.
\end{abstract}

Keywords: woman, violence, protection, abuse, defense 


\section{Introducción}

En este artículo se presentan los casos de violencia que sufrieron la valenciana Beatriz Martí y la princesa troyana Andrómaca. Las informaciones que existen sobre la noble valenciana se deben, principalmente, a la correspondencia de la reina de Aragón, María de Castilla; mientras, para la princesa troyana hay un legado histórico-legendario y literario que procede de la mitología griega, los poemas épicos del ciclo troyano (como la Iliupersis y la Ilíada de Homero) y las tragedias Troyanas y Andrómaca del dramaturgo Eurípides.

Evidentemente, ellas eran dos mujeres cuya vida transcurrió en lugares y épocas diferentes: Beatriz vivió en la Corona de Aragón a finales de la Edad Media y Andrómaca en Troya y, posteriormente, en Grecia durante la Edad del Bronce. Pero, a pesar de la distancia cronológica que separa a ambas mujeres, hay cosas que las unen, tanto como el sufrimiento, la angustia y el dolor por la injusticia, el desprecio y el maltrato cometidos contra ellas, como también el hecho de poder contar con una persona que les defiende.

Para los fines de nuestro análisis, es preciso que se mencionen algunos datos, de manera somera y muy resumida, sobre la situación de la mujer griega antigua y la mujer medieval. Este hecho nos ayudará, sin duda, a tener una idea más clara sobre el trasfondo social de los casos tratados.

\section{La condición social de la mujer griega antigua y la mujer medieval}

Desgraciadamente, el menosprecio y la violencia contra las mujeres existen como problemas muy graves desde la Antigüedad hasta hoy en día. Concretamente, en la Antigua Grecia, la sociedad trataba a la mujer como un ser inferior, ${ }^{1}$ como una menor que necesitaba siempre la tutela de un varón (padre, hermano, esposo, hijo u otro familiar masculino). Las mujeres griegas, especialmente las atenienses y en menor medida las espartanas, ${ }^{2}$ estaban privadas de la vida social pública (excepto

1 Esta mentalidad se basó, principalmente, en las afirmaciones de Hipócrates, Aristóteles y Galeno sobre la inferioridad biológica de las mujeres ante la potencia varonil (Aristóteles 1992: I, 728a).

2 En Esparta las mujeres disfrutaban de mayor libertad que en otras regiones de Grecia. En concreto, las espartanas recibían, al igual que los hombres, una educación física, recomendada por el Estado, con el fin de engendrar hijos saludables que se convirtieran en guerreros fuertes (algo imprescindible para una ciudad que se encontraba en constantes conflictos bélicos) (Jenofonte 1984; Plutarco 1985 y Cicerón 2008). 
Anastasia Terzopoulou. Violencia conyugal y víctimas de la guerra: la valenciana Beatriz Martí y la troyana Andrómaca de Eurípides

algunas fiestas religiosas), y no tenían los mismos privilegios ni derechos que los hombres. ${ }^{3}$ En otras palabras, las mujeres griegas quedaban relegadas dentro del ámbito privado de su oĩ (hogar) ocupándose de las tareas domésticas, siendo su mayor prioridad la procreación y el cuidado de sus hijos.

Dentro de esta sociedad patriarcal, la vida de las esclavas, como la que vivió Andrómaca tras el asedio de Troya en la casa de sus enemigos, era aún más dura, ya que ellas se encontraban sometidas a la total disposición de sus amos. ${ }^{4}$

Tampoco en la Edad Media el clima fue propicio para los derechos de la mujer. ${ }^{5}$ Específicamente, según el pensamiento teológico medieval, la mujer era considerada como un ser lleno de defectos, propenso a la tentación y a los vicios, representado por la figura bíblica de $\mathrm{Eva}^{6}$ (Weisl 1998). Sólo a partir de los siglos XIII y XIV empezó a realizarse un cambio con la aparición de algunas órdenes religiosas femeninas, ${ }^{7}$ las cuales, a pesar del refugio que ofrecieron a muchas mujeres maltratadas, propiciaron también su educación intelectual. Además, existieron muchas figuras femeninas cultas e influyentes que mostraron su solidaridad a las mujeres víctimas de violencia de género de su sociedad.

3 Las mujeres griegas no podían ocupar ningún cargo administrativo, jurídico ni político; y, además, su formación educativa era muy elemental. No obstante, había casos de mujeres que lograron obtener una educación más avanzada, como, por ejemplo, Agnódice, la primera médica griega (Pomeroy 1977).

4 Las esclavas realizaban todas las labores domésticas bajo la supervisión de la señora de la casa y, también, satisfacían los deseos eróticos de su amo. Además, según la voluntad de su señor, podían ser liberadas o vendidas a otro propietario (Pomeroy, 1991: 109-110).

5 En la Edad Media, como en la Antigüedad, el rol de la mujer era el de la buena esposa, madre y guardiana de su hogar. Las mujeres de origen social más humilde y, generalmente, las campesinas realizaban tareas muy duras con el fin de ayudar al sostenimiento de su familia, pero su trabajo era siempre menospreciado en comparación con el masculino. Tampoco tenían una educación igualitaria. Sólo las mujeres de alto rango social podían tener acceso a una formación más elevada (Fossier 1996).

6 Según la mentalidad de la sociedad medieval, la figura virtuosa de la Virgen María constituía un modelo a seguir para las mujeres (especialmente para las hijas solteras). También, la figura de María Magdalena, como mujer arrepentida, sirvió de modelo para las mujeres casadas y viudas, a las cuales se les permitió el ingreso en conventos y órdenes religiosas (Weisl, 1998: 172).

7 Las más importantes órdenes femeninas eran las carmelitas, las franciscanas (clarisas), las cistercienses y las dominicas.

SCRIPTA, Revista internacional de literatura i cultura medieval i moderna, núm. 16 / desembre 2020 / pp. 279-299 ISSN: 2340-4841 · doi:10.7203/SCRIPTA.16.19231 


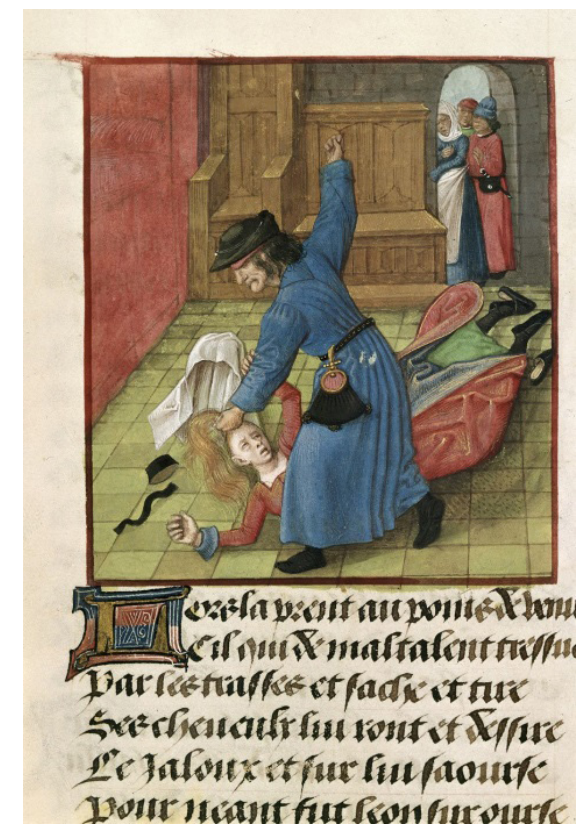

Fig. 1. Mujer maltratada por su esposo celoso. Detalle del manuscrito ilustrado Roman de la Rose. British Library Harley 4425, fol. 85, (c. 1490-1500). Imagen obtenida de British Library. [Disponible en http://www. bl.uk/manuscripts/Viewer.aspx?ref=harley ms 4425 fs001r] .

Sin lugar a duda, se esperaría que la violencia marital fuera una plaga que sufrían más las mujeres de las bajas clases sociales. Pero la violencia y los malos tratos reinaban también dentro de las cortes reales. Muchos casos de violencia conyugal se han documentado sobre mujeres de gran rango social (entre ellas, marquesas, duquesas y hasta reinas), y no faltaron los casos de criadas de las víctimas que acudieron en su ayuda o denunciaron los maltratos con el fin de que se evitara hasta el femicidio. ${ }^{8}$ Este misoginismo era la razón por la creación de la «Querella de las mujeres», ${ }^{9}$ un movimiento intelectual de resistencia femenina que recibió en España su mayor impulso en la Corona de Aragón bajo el apoyo de la reina María de Aragón, cuya solidaridad en casos de violencia marital era importantísima, como la que se va a tratar en este artículo. Pero empecemos desde el tema de Andrómaca, cuya historia nos la ofrece la mitología griega.

\footnotetext{
8 La Ley castigaba los casos más severos de violencia contra las mujeres.

9 Durante los últimos años de la Edad Media la mujer empezó a tomar conciencia de sus injusticias sufridas, tanto intrafamiliares como extrafamiliares, reivindicando un cambio sobre su condición socio-política y cultural a través de la Querelle des femmes y su obra más representativa: el Libro de la Ciudad de las Damas (Le Livre de la Cité des Dames, 1405) de Christine de Pisan (1364-1430). En la Corona de Aragón este movimiento intelectual encontró su mejor representante a la figura de Isabel de Villena (1430-1490) y su obra Vita Christi, de 1497 (Ramírez, Martín, Aguilar \& Cerrato 2011).
} 
Anastasia Terzopoulou. Violencia conyugal y víctimas de la guerra: la valenciana Beatriz Martí y la troyana Andrómaca de Eurípides

\section{Andrómaca como víctima de la guerra troyana dentro de la tragedia homónima de Eurípides}

Eurípides (480 a.C.-406 a.C.) se ocupa del tema de la guerra troyana y sus terribles consecuencias sobre sus víctimas en tres de sus dieciocho tragedias conservadas: Andrómaca (c. 425 a. C.), Hécuba (424 a.C.) y las Troyanas (415 a.C.). Como se ha indicado en la parte introductoria, el gran ateniense dramaturgo presenta en dos de éstas la cruel realidad que está obligada a vivir Andrómaca, ${ }^{10}$ la cual se ha convertido, tras el asedio y la caída de Troya (en 1184 a.C.), desde esposa del mejor guerrero y heredero al trono troyano Héctor ${ }^{11}$ en esclava y concubina de Neoptólemo, quien es uno de los destructores de Troya, ${ }^{12}$ asesino de su suegro y de su hijo Astiánacte, ${ }^{13}$ y, también, hijo del caudillo de los mirmidones Aquiles, asesino de su familia natural ${ }^{14}$ y de su queridísimo esposo. Como se puede comprender, la heroína experimenta un dolor profundo e irreparable tanto por la pérdida de sus seres queridos y de su patria, como también por su condición social actual.

Más detalladamente sobre el tema que nos atañe, Andrómaca, en la homónima tragedia de Eurípides, tras las desgracias sufridas por los griegos en Troya, vive ya en Ptía de Grecia con su nuevo amo, de quien ha tenido un hijo varón. ${ }^{15}$ Pero la vida de la heroína se complica aún más cuando Neoptólemo recibe como esposa legítima a Hermíone, hija de los reyes espartanos Menelao y Helena. ${ }^{16}$

Concretamente, el origen de los nuevos sufrimientos de la troyana son los celos que siente la joven reina por la fertilidad de Andrómaca y, a la vez, el miedo ante la posibilidad de ser repudiada por su marido debido a su propia falta de descendencia. Así pues, cuando Neoptólemo va al templo del dios Apolo en Delfos, Hermíone encuentra la mejor oportunidad para acabar con madre e hijo. Ante este peligro, Andrómaca esconde a su hijo fuera del palacio y busca asustada protección en el

10 Andrómaca era hija de Eetión, rey de Tebas de Misia, ciudad próxima a Troya (Grimal 1951: 27).

11 Héctor era el primogénito hijo de los reyes de Troya, Príamo y Hécuba, y hermano de Paris y Casandra, entre otros (Grimal 1951: 225-226).

12 Neoptólemo fue uno de los griegos que entraron en la ciudad troyana escondido dentro del llamado «Caballo de

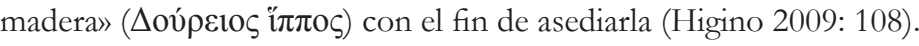

13 Esto sucedió según la Pequeña Ilíada. En la Ilimpersis se menciona que Odiseo mató a Astiánacte.

14 Durante la expedición de los griegos contra Troya, la patria natal de Andrómaca fue asediada y su padre y sus hermanos encontraron la muerte a manos de Aquiles, quien, también, raptó a su madre, la cual, finalmente, sucumbió a su dolor (Grimal 1951: 27).

15 Se trata de su hijo llamado Moloso. Según la tradición, Andrómaca había tenido con Neoptólemo, aparte de Moloso, dos hijos más, Pielo y Pérgamo (Grimal 1951: 27).

16 Helena, hija del rey espartano Tindáreo y de la princesa etólia Leda, había provocado la guerra de Troya debido a su fuga (o rapto) por el príncipe troyano Paris (Grimal 1951: 231).

SCRIPTA, Revista internacional de literatura i cultura medieval i moderna, núm. 16 / desembre 2020 / pp. 279-299 ISSN: 2340-4841 · doi:10.7203/SCRIPTA.16.19231 
Anastasia Terzopoulou. Violencia conyugal y víctimas de la guerra: la valenciana Beatriz Martí y la troyana Andrómaca de Eurípides

altar de la diosa Tetis $^{17}$ (vv. 42-44, 47-51). ${ }^{18}$ Desde este lugar sagrado empieza a lamentar sus penas y solicita la intervención de Peleo mediante una esclava troyana (vv. 56-102). Entonces, aparece Hermíone e inculpa a la otrora princesa de Troya por el desprecio de su marido Neoptólemo expresando, mediante intimidaciones, humillaciones e insultos (vv. 155-177, 257, 259), todo su odio hacia la heroína. ${ }^{19}$


de la lanza», v.155) que no le permite expresarse libremente, no aguanta la injusticia sufrida y, como persona que se respeta a sí misma y se mantiene fiel a sus nobles principios (v. 191), intenta defenderse de los insultos y las falsas acusaciones ${ }^{20}$ (vv. 194-206, 222-228). Mientras tanto, llega el padre de Hermíone y trata de apartar a Andrómaca del altar pidiéndole que se sacrifique a cambio de la salvación de su hijo (vv. 380-383). La troyana en vano les advierte que Neoptólemo deseará vengarse de este abominable e injusto acto contra la vida de su hijo (vv. 336-348). También trata de explicarles que ella no tiene la culpa, ya que es una víctima, una esclava sin derechos, un botín de guerra que trajo consigo Neoptólemo y con quien ha tenido un hijo sin su propia voluntad (vv. 390-391).

Sin embargo, el amor maternal de Andrómaca la conduce a aceptar a ofrecer su propia vida (vv. 410-412), pero pronto comprende que todo es una trampa, ya que padre e hija han decidido cautivar y matar a ambos (vv. 425-434, 442, 444).

Se podría decir que Andrómaca se encuentra en la misma situación que en la que vivió con su hijo Astiánacte tras la caída de la ciudad troyana, ya que ella está una vez más sola, llena de miedo y sin protección ante las amenazas de muerte de su hijo. Resulta claro que la inferioridad social de la troyana, como mujer extranjera y esclava, la condiciona y la impide obrar de manera libre para poder proteger a su hijo. Ni sus propias súplicas, como tampoco las lágrimas de su hijo logran ablandar el corazón de sus acosadores (vv. 526-536, 537-540). Su única esperanza de salvación es la ayuda del anciano rey Peleo, abuelo paterno de Neoptólemo y, por lo tanto, bisabuelo de su hijo.

17Según la mitología griega, Tetis era una ninfa del mar, esposa del rey Peleo y madre del guerrero Aquiles (Grimal 1951: 511).

$18 \mathrm{El}$ análisis del tema sobre la tragedia Andrómaca de Eurípides, a partir de Eurípides (1990).

19 Tanto los insultos de Hermíone (vv. 147-180), como las propias palabras de Andrómaca (vv.1-55, 96-116) describen el cruel destino que aguardó la vida a la heroína a partir del momento que perdió a su esposo Héctor y se convirtió en cautiva de guerra en la casa de sus enemigos. Indudablemente, la descripción de la vida de Andrómaca como esclava en la tragedia euripídea tiene su eco en los pensamientos que realiza Héctor sobre el amargo futuro de su esposa, durante la emotiva escena de su despedida en la Ilíada de Homero (Eurípides 1990: vv. 441-465).

20 Hermíone supone que Andrómaca provocó su esterilidad mediante fármacos con el fin de que su hijo ilegítimo se apoderara de la casa real. Andrómaca intenta defenderse de estas sospechas irracionales y acusa a Hermíone de su

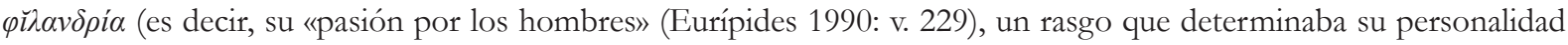
moral, como la de su madre Helena, provocando muy malas consecuencias (véase nota núm. 16).

SCRIPTA, Revista internacional de literatura i cultura medieval i moderna, núm. 16 / desembre 2020 / pp. 279-299 ISSN: 2340-4841 · doi:10.7203/SCRIPTA.16.19231 
Anastasia Terzopoulou. Violencia conyugal y víctimas de la guerra: la valenciana Beatriz Martí y la troyana Andrómaca de Eurípides

Efectivamente, cuando llega Peleo, Andrómaca le expone el peligro que corren tanto ella como su hijo e implora su apoyo (vv. 559 - 576):

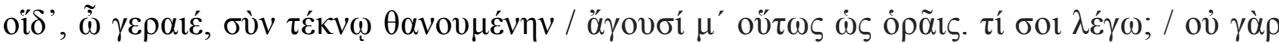

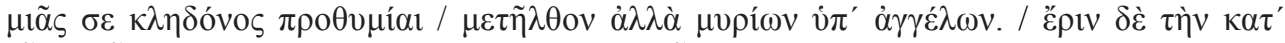

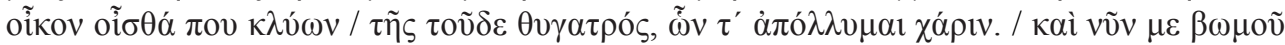

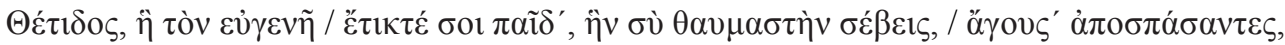

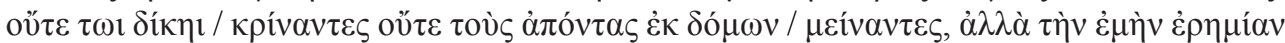

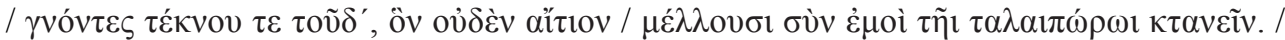

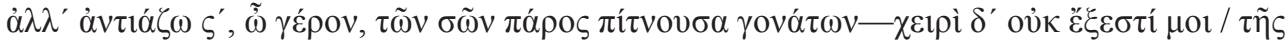

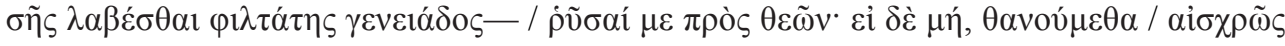

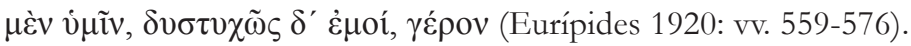

(estos, oh anciano, me llevan a morir con mi hijo tal como ves. ¿Qué te voy a decir? No te mandé buscar con el celo propio de una sola llamada, sino por innumerables mensajes. La discordia que hay en casa por obra de la hija de éste la sabes por haberla oído en alguna parte, y también por qué motivo perezco. Ahora me conducen después de haberme arrancado del altar de Tetis, la que para ti dio a luz a tu noble hijo, a la que tú veneras como digna de admiración, sin haberme condenado en juicio alguno y sin esperar a los que estaban ausentes del palacio, sino con conocimiento de mi soledad y la de este hijo mío, a quien, sin culpa ninguna, se disponen a matar conmigo, la desdichada. Pero te suplico, oh anciano, postrándome delante de tus rodillas — pues no me es posible coger tu queridísima barba con la mano— que me defiendas, por los dioses. Si no, moriremos, de modo ultrajante para vosotros y desdichado para mí, anciano.) (Eurípides 1990: vv. 559-576).

Inmediatamente, Peleo ordena que los liberen de sus ataduras (vv. 577-578), pero Menelao insiste en su decisión de matarlos y reprocha al anciano rey su tolerancia y su buen comportamiento hacia una extranjera que, a pesar de haber sido pariente del asesino de su hijo Aquiles, ${ }^{21}$ parece capaz de apoderarse del reino gracias a su hijo y a la infertilidad de Hermíone (vv. 645 - 670).

\footnotetext{
21 Según la versión más extendida, Paris mató a Aquiles mediante una flecha en su talón para vengarse de la muerte de su hermano Héctor (Burgess 1995: 217).
} 


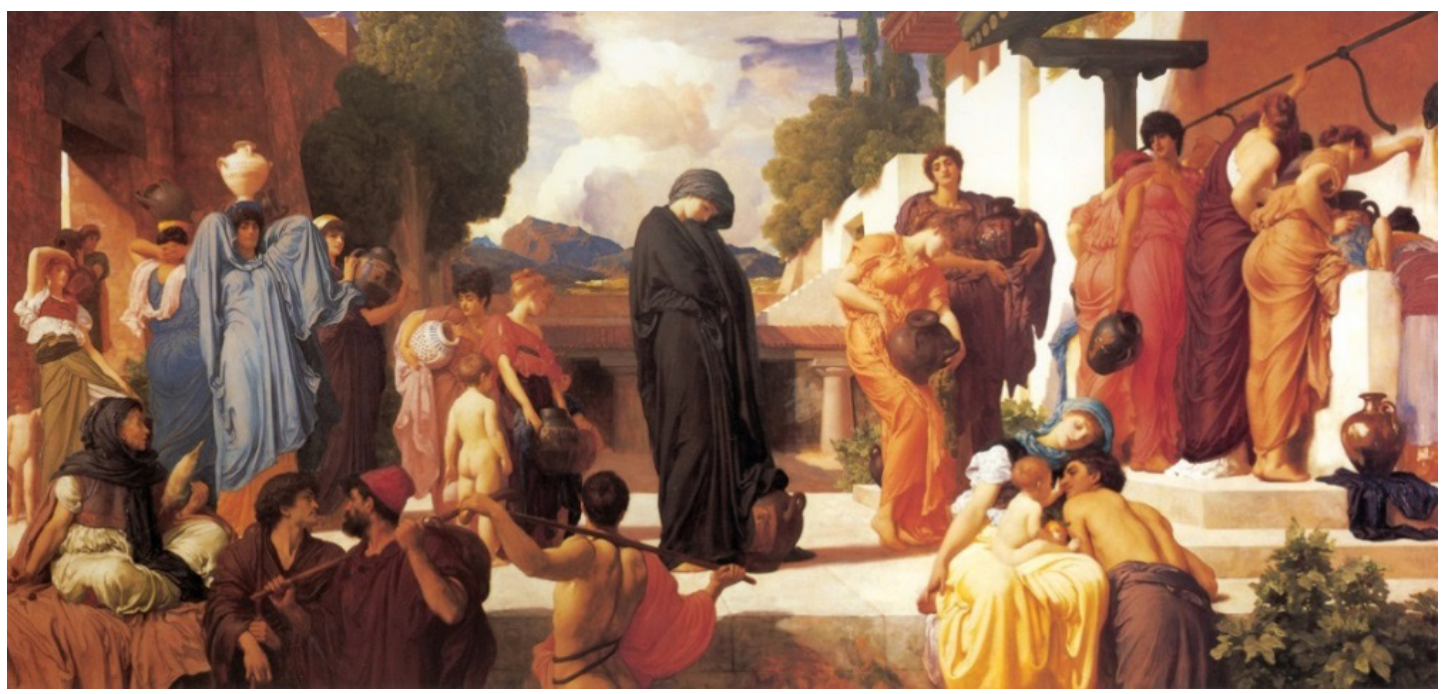

Fig. 2. Andrómaca cantiva (Captive Andromache, ca. 1886 - 1888) de Frederic Leighton. Galería de Arte de

Manchester, Reino Unido. Imagen obtenida de Wikimedia Commons. [Disponible en $<\underline{\text { https://commons. }}$ wikimedia.org/wiki/File:Leighton Captive Andromache.jpg >].

Entonces, Peleo empieza un discurso acusativo (vv. 590-641), ${ }^{22}$ con el fin de demostrar que la troyana y su hijo son agraviados de manera deshonesta sufriendo las consecuencias de una situación sin ser culpables. En efecto, el anciano rey logra desacreditar la falaz imagen del espartano como glorioso rey y guerrero al recordarle su cobardía en el campo de batalla durante la guerra troyana, su vil participación en el sacrificio de su sobrina Ifigenia en Áulide y, sobre todo, su débil carácter ante su deshonesta mujer Helena. Además, sus palabras sobre el verdadero valor de las personas de humilde condición social, pero de noble corazón -como Andrómaca y su hijo-, frente a las personas de alto rango social sin virtudes -como Menelao y su familia-, provocan molestia al padre de Hermíone, quien, finalmente, ante la posibilidad de recibir el castigo de Neoptólemo, se muestra cobarde una vez más y se va a Esparta ${ }^{23}$ utilizando nimias justificaciones (vv. 729-736). También Hermíone se arrepiente de su actitud y retrocede en sus viles planes (vv. 802-865).

Indudablemente, la intercesión de Peleo, a pesar de su avanzada edad, es significativa para la salvación de madre e hijo. Gracias a la fuerza de su espíritu el anciano rey los defiende ${ }^{24}$ y refuta

22 Véase el apartado Documentos núm. 1.

$23 \mathrm{M}$ enelao aparece cobarde y egoísta, ya que deja a su hija sin protección y se va. Entonces, Hermíone, ante el temor de la llegada de Neoptólemo, desea morir.

24 Véase los versos 577-578, 581-582, 586, 588, 590-641, 693-726 (Eurípides 1990).

SCRIPTA, Revista internacional de literatura i cultura medieval i moderna, núm. 16 / desembre 2020 / pp. 279-299 ISSN: 2340-4841 · doi:10.7203/SCRIPTA.16.19231 
Anastasia Terzopoulou. Violencia conyugal y víctimas de la guerra: la valenciana Beatriz Martí y la troyana Andrómaca de Eurípides

las infundadas acusaciones que había expuesto el cínico Menelao ${ }^{25}$ en su contra, liberándoles de su cautividad (vv.719-723, 725). Sin lugar a dudas, Peleo, como una persona muy virtuosa, es lógico que se indigne ante la injusticia y la violencia cometidas contra Andrómaca y su hijo, hecho que

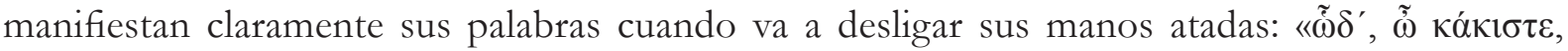

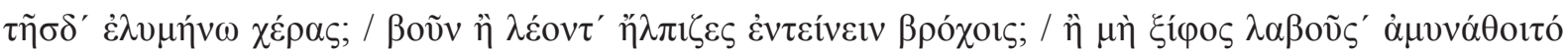

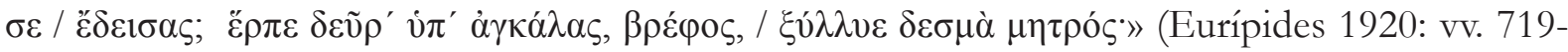
723). (¿Así, oh malvadísimo, has maltratado las manos de ésta? ¿Creías sujetar con los nudos corredizos un buey o un león? ¿ंO es que temiste que ella, cogiendo una espada, te rechazara? Ven aquí bajo mis brazos, criatura, y colabora en soltar la atadura de tu madre.) (Eurípides 1990: vv. 719-723).

Cabe señalar que Andrómaca, a pesar de su condición de esclava y la violencia sufrida, tanto física como también verbal y psicológica, aparece superior en lo que se refiere a la nobleza y la virtud de su carácter en comparación con la señora de la casa Hermíone.

Además, en este punto hay que destacar que la mayor culpa la tiene Neoptólemo, quien ha obligado a que convivan bajo el mismo techo dos mujeres, hecho que provocó la indignación y los celos de su esposa. Como se puede percibir, se trata de una situación incómoda para ambas mujeres, pero Hermíone no tiene el derecho a atacar a Andrómaca y, cuanto menos, a su inocente hijo, quienes se encuentran impactados emocionalmente y sólo tras el apoyo de Peleo logran aliviar su ansia (vv. 747-749, 757-765).

\section{Beatriz Martí, una víctima de violencia conyugal en la Corona de Aragón bajomedieval}

En el caso de la valenciana Beatríz Martí, la preocupación de María de Castilla, reina de Aragón (1401-1458), ${ }^{26}$ es la que nos informa sobre la situación de la violencia marital que sufrió la noble dama a través de unas cartas que había enviado la soberana, a principios de la década de los cincuenta del siglo XV, tanto al esposo de ésta, mosén Perot Pardo, y al doncel don Joan de Montpalau, su consejero real; como también de unas copias que había mandado a su primera dama y amiga íntima Isabel Maza en su intento de notificarle sobre los hechos. ${ }^{27}$

25 Eurípides expresa a través de las acusaciones de Andrómaca (vv.445-463) y de Peleo (vv. 590-641, 693-726) hacia Menelao su opinión contra la sociedad espartana, el gran enemigo de Atenas en la guerra del Peloponeso (431 a.C.-404 a.C.) (Hose 2008: 80).

26 Doña María era hija del rey Enrique III «el Doliente», rey de Castilla, y de Catalina de Lancáster, nieta del rey Pedro I de Castilla y del rey Eduardo III de Inglaterra. También era hermana de Juan II de Castilla, padre de Enrique IV e Isabel la Católica. Tras su matrimonio con Alfonso V el Magnánimo en 1415 se convirtió en reina consorte de la Corona de Aragón, Sicilia y Nápoles (Earenfight 2010).

27 Por este dato se puede deducir que doña Isabel fue la persona que informó a la reina María sobre los malos tratos que recibía doña Beatriz de su esposo.

SCRIPTA, Revista internacional de literatura i cultura medieval i moderna, núm. 16 / desembre 2020 / pp. 279-299 ISSN: 2340-4841 · doi:10.7203/SCRIPTA.16.19231 
Anastasia Terzopoulou. Violencia conyugal y víctimas de la guerra: la valenciana Beatriz Martí y la troyana Andrómaca de Eurípides

Cabe señalar que doña Beatriz Martí pertenecía a una de las más grandes y nobles familias bajomedievales de la Corona de Aragón; ${ }^{28}$ y, según las descripciones de la soberana en una de sus cartas, se trataba de una mujer «bona, honesta e ab bon seny». ${ }^{29}$ Igualmente, su esposo, mosén Perot Pardo, ${ }^{30}$ constituía una de las personas más influyentes y poderosas del reino, ya que procedía de la más importante y acaudalada familia judeoconversa de comerciantes de Mallorca. $^{31}$

La reina María, debido a su carácter virtuoso y justo, siempre interponía su persona en todo tipo de injusticias y problemas que sufrían las personas de todas las clases sociales de su reino. ${ }^{32}$ Así, al informarse de la difícil y humillante situación de doña Beatriz sintió la obligación de intervenir como mediadora. ${ }^{33}$ Sin lugar a duda, la indignación de la reina crecía sobre el mal comportamiento de Pardo, quien parece que no la hacía caso. Por ese motivo, la reina le enviaba cartas asiduamente, cuyo tono cambiaba de manera constante y gradual: al principio le aconsejaba, luego le increpaba e intimidaba y, finalmente, intentaba convencerla mediante recompensas.

28 Beatriz Martí era sobrina de Galcerà Martí, suegro del aragonés Lluís de Santàngel (c.1435-1498) que se convirtió en consejero y escribano de ración de los Reyes Católicos, Fernando II de Aragón (1479-1516) e Isabel I de Castilla (1479-1504), contribuyendo a la financiación de la primera expedición del almirante Cristóbal Colón hacia América en 1492 (Vidal 1991).

29 Concretamente, se trata de la misiva del 17 de marzo de 1452 que había enviado la reina María al doncel don Joan de Montpalau con el fin de que éste interviniera en su nombre a mosén Perot Pardo sobre el caso del maltrato. Cf. Archivo de la Corona de Aragón (en adelante, ACA), Cancillería Real (en adelante, CR), Registro (en adelante, Reg.) 3275, ff. 25-25v. Véase el apartado Documentos núm. 2.

30 Para el noble mercader Perot Pardo, su casamiento con Beatriz Martí era el segundo, ya que antes había contraído matrimonio con Damiata de Castellví, viuda del caballero Manuel de Montagut (Sáiz Serrano 2008: 317).

31 También los hijos de mosén Perot Pardo con doña Beatríz realizaron enlaces matrimoniales con familias de gran importancia en la mercadería de la isla (Vidal 2007: 30).

32 También, en Castilla existían casos que requerían su mediación solidaria donde contaba con el apoyo de su madre, Catalina de Lancaster, regente de Castilla (1372-1418) (Echevarría 2002).

33 Según se cuenta, la propia reina había sufrido el maltrato marital del rey Alfonso V y, por lo tanto, podía fácilmente identificarse con casos de violencia conyugal. Sin embargo, hay una carta que envió doña María a su madre con el fin de aliviar su preocupación por los rumores sobre la infidelidad del rey aragonés (ACA, CR, Reg. 3162: f. 66v).

SCRIPTA, Revista internacional de literatura i cultura medieval i moderna, núm. 16 / desembre 2020 / pp. 279-299 


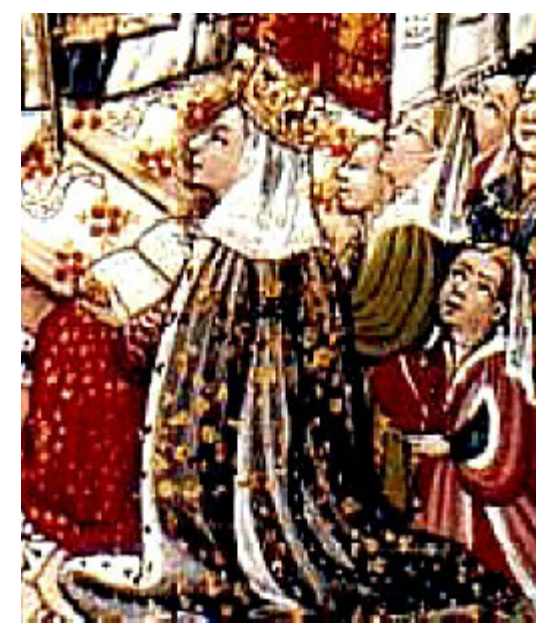

Fig. 3. María de Castilla, reina consorte de Aragón. Detalle de una ilustración del siglo XV. Imagen obtenida de Wikimedia Commons. [Disponible en <https://commons.wikimedia.org/wiki/File:Marie_Kastilie.jpg].

Más en concreto, en la carta del 15 de marzo de 1452, la soberana habla de una situación que ninguna mujer honrada podría soportar y, por eso, le aconseja a mosén Perot que cambie de actitud hacia su esposa, exhortándole a vivir según las leyes humanas y la de Dios. Además, le advierte sobre las malas consecuencias que tendría su reputación como caballero si surgiera un escándalo dentro de la sociedad valenciana. A través de esta mención se puede comprender claramente que la reina quería que se evitaran las disputas dentro de la corte real, ya que los familiares implicados eran personas muy poderosas. A continuación, le menciona que en el caso de que él rectifique su comportamiento hacia su afligida esposa, le va a recompensar como buen servidor suyo. En la parte final de la carta le informa que le enviará al doncel don Joan de Montpalau para que éste le exponga de cerca sus intenciones (ACA, CR, Reg. 3275: ff. 24-25v). ${ }^{34}$

En efecto, dentro de dos días doña María envió una carta a su consejero real para que éste solucionara el asunto de manera discreta y eficaz, es decir exactamente tal como lo llevaría a cabo ella misma. En esta misiva la reina expresa de manera explícita su ansia sobre los escándalos que pueden surgir dentro de la sociedad del reino, ya que los parientes de la apenada y humillada esposa de mosén Perot están dispuestos a hacer lo que sea necesario para protegerla. Concretamente, la reina menciona característicamente:

\footnotetext{
no cessa de donar mala vida a la dita noble, e metre en algun perill axi della com de seguirse entre los parents de la dita dona e lo dit noble scandols e inconvenients per voler preservar aquella de tal vida (ACA, CR, Reg. 3275: ff. 25-25v). ${ }^{35}$
}

34. Véase el apartado Documentos núm. 2.

35 Véase el apartado Documentos núm. 3. 
Y aunque no se sabe sobre el tipo del maltrato que sufrió doña Beatriz, es decir violencia física, simbólica o psicológica, o todo junto, como sucede en la mayoría de los casos; lo seguro es que la situación requería una solución rápida y eficaz, como sucedió en el caso de la troyana Andrómaca que se analizó anteriormente. Ciertamente, parece que la reina había recibido informaciones muy preocupantes sobre la deshonrada actitud de mosén Perot Pardo que la hacían pensar que, en caso de que no se encontrara lo antes posible un remedio, habría muy malas consecuencias que harían peligrar el bienestar de doña Beatriz. Por lo tanto, la mediación del doncel valenciano resultaba prioritaria e inminente. ${ }^{36}$

Pero tampoco este intento mediador tuvo eficacia hasta que, finalmente, la reina logró su objetivo en junio de 1452 mediante la vía de diplomacia, consiguiendo que su esposo, el rey Alfonso $\mathrm{V}$ el Magnánimo, le concediera el alto cargo del conservador de su patrimonio en el Reino de Mallorca. Incluso, la reina se ocupó personalmente del asunto notificando al gobernador de la isla, mosén Arnau de Vilademany y de Blanes, los hechos (ACA, CR, Reg. 3275, f. 59v).

Basándose en el contenido de las cartas, se puede deducir que el mal comportamiento de mosén Perot Pardo se debía a su carencia de lealtad hacia su esposa. Sin lugar a dudas, la violencia simbólica es un abuso psicológico muy fuerte que provoca a las víctimas sentimientos muy malos y desagradables, como aflicción, culpabilidad, desconfianza, tristeza, desengaño e ira; y les conduce a tener una autoestima muy baja y negativa, poniendo muchas veces en riesgo su bienestar físico y psíquico. El papel del entorno familiar y social juega también un papel muy importante, ya que puede influir en la psicología de la persona afectada de manera considerada. No hay que olvidar que en caso de infidelidad, el entorno social es el que suele sacar más fácilmente sus propias conclusiones «condenando» y «castigando» no sólo a la persona que ha realizado el engaño, sino también a la persona engañada. Y esto es algo que pasa, desafortunadamente, a lo largo de los siglos en la mayoría de las sociedades del mundo.

Dentro de este marco ha de considerarse que las cosas para doña Beatriz, una dama de la nobleza medieval, eran aún más difíciles, ya que el desamor, el engaño y el desprecio recibidos por su esposo impactaban negativamente su imagen pública y social, y, a la vez, la afectaban personalmente, haciéndola sentirse muy afligida e infravalorada como mujer. Se diría, pues, que la decisión de la reina de ofrecer a mosén Perot Pardo un cargo tan importante en otro lugar no fue sólo para persuadirle de que él cambiara de actitud hacia su esposa legítima con el fin de protegerla del maltrato sufrido, sino también para alejar al matrimonio de las miradas indiscretas de la sociedad valenciana, ofreciendo, así, alivio a la noble dama.

36 A pesar de ser una persona de confianza de la corte real, el doncel don Joan de Montpalau sostenía lazos familiares con la familia de doña Beatriz y, por consiguiente, la soberana creía que su intervención tendría mucho peso (ARV, Maestre Racional, 472: f. 6v). 
Anastasia Terzopoulou. Violencia conyugal y víctimas de la guerra: la valenciana Beatriz Martí y

la troyana Andrómaca de Eurípides

\section{Conclusiones}

A través de este artículo se han expuesto los casos de violencia contra la troyana Andrómaca y la valenciana Beatriz Martí, verificando que, por desgracia, el maltrato de género existía como problema muy severo desde la Antigüedad y ha perdurado a lo largo de los siglos hasta la actualidad.

En el caso de la heroína troyana, el tema de la violencia es tratado por el dramaturgo Eurípides desde varios aspectos, ya que Andrómaca sufre los malos tratos tanto como mujer como también como víctima de guerra. Ella, tras perder a sus familiares y su patria, sufre también la humillación social, ya que desde princesa y futura reina de Troya se ha convertido en una esclava que vive dentro de un miedo constante.

Otro aspecto importante que hay que destacar en este punto es que dentro del caso de Andrómaca surge el problema de Hermíone, cuyos celos e ira, como mujer ultrajada y repudiada por su esposo, la conducen a cometer atrocidades contra la inocente Andrómaca y su hijo.

Igualmente agraviada es la valenciana doña Beatriz que sufre el maltrato marital y el desprecio dentro de una sociedad llena de prejuicios y completamente estereotipada. Sin embargo, como ya hemos analizado, tanto Andrómaca como Beatriz Martí reciben el apoyo y la protección de dos personas muy importantes.

Por otra parte, podría deducirse que en ambos casos tanto Peleo, el anciano rey de Ptía, como la reina María de Aragón tienen sus propios intereses para desear la salvación de las víctimas. Obviamente, Peleo quería amparar a Andrómaca y a su hijo para preservar la descendencia de su nieto y, por consiguiente, su patrimonio familiar; mientras, en el caso de doña Beatriz, la reina María deseaba que se evitaran los conflictos dentro de los miembros de su corte.

Sea como fuese, lo que resulta evidente es que ambos reyes muestran buena voluntad e intentan ofrecer su amparo a estas mujeres agraviadas. En efecto, doña María sabe que los escándalos que podrían surgir de las disputas entre los familiares y los miembros de la corte real resultarían perjudiciales para el estado psíquico de doña Beatriz y, por lo tanto, la soberana trata de evitarlos. Del mismo modo, el rey Peleo se indigna ante las injusticias cometidas contra la desprotegida e inculpable Andrómaca.

En síntesis, ambos casos manifiestan que cualquier aspecto del maltrato -físico, emocional, verbal, psicológico o sexual-, trae muy malas consecuencias para las víctimas y, por ese motivo, debe ser condenado por la sociedad con el fin de que se erradique para siempre. Por consiguiente, cada uno de nosotros tiene la obligación de salvaguardar la vida y los derechos femeninos. 


\section{Documentos}

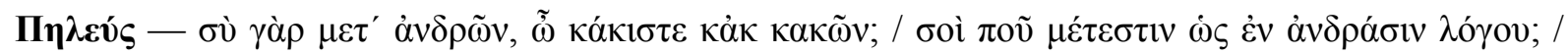

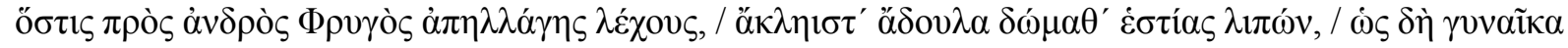

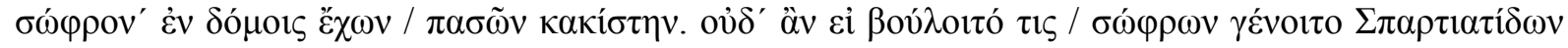

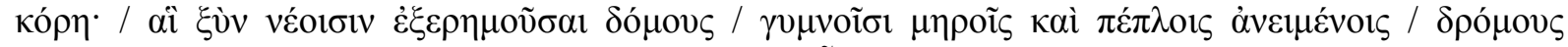

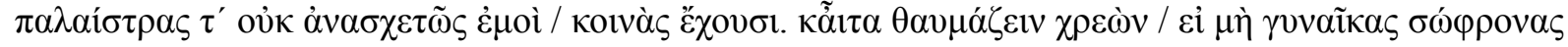

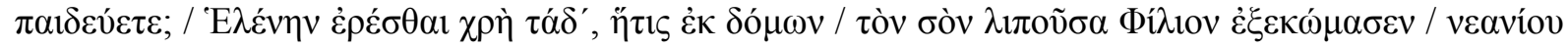

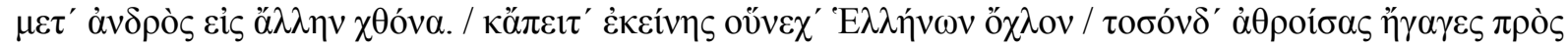

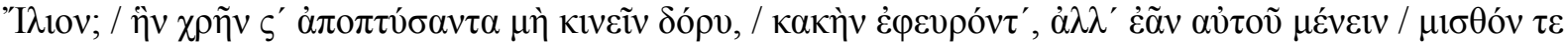

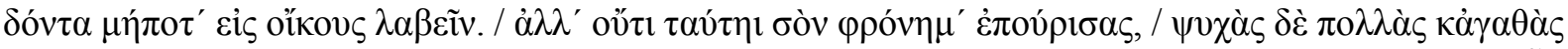

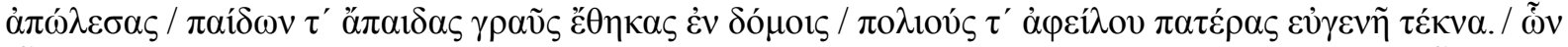

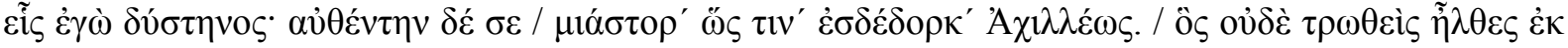



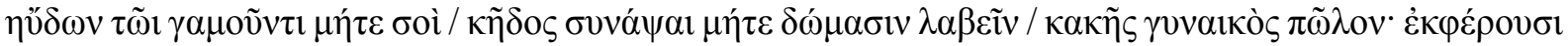

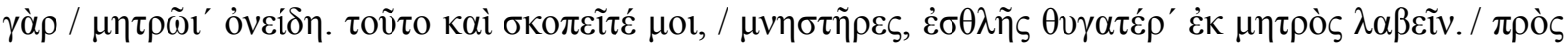

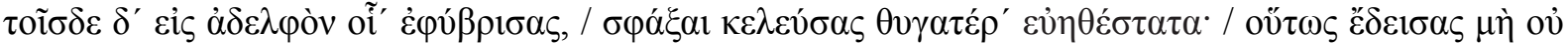

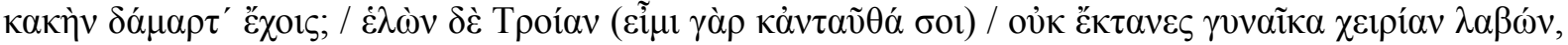

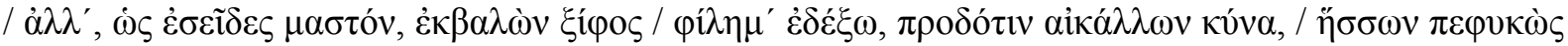



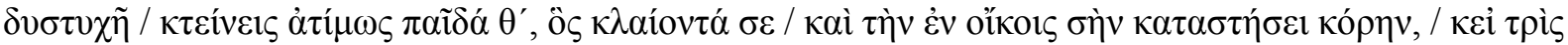

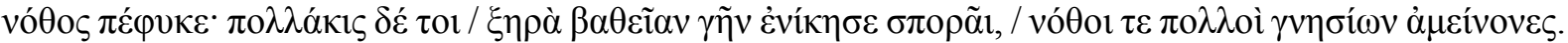

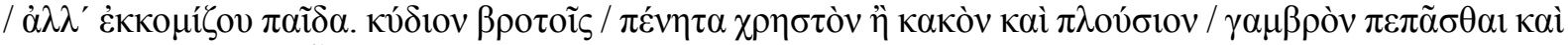

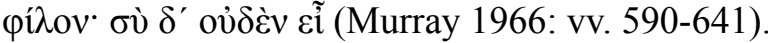

—Eurípides (1990/1998). Tragedias. Obra completa. El Cíclope. Alcestis. Medea. Los Heraclidas. Hipólito. Andrómaca. Hécuba, Medina González, A. / López Férez, J. A. (eds.), Madrid, Editorial Gredos, vol. 1. [1990, $1^{\mathrm{a}}$ edición, $5^{\mathrm{a}}$ impresión], pp. 411-413.

PELEO. - ¿Te cuentas tú entre los hombres, oh malvadísimo e hijo de malvados? ¿En qué te corresponde a ti contarte entre hombres? Tú que fuiste privado de tu esposa por un frigio, por haber dejado las salas de tu hogar sin cerrojo y sin esclavos, como si tuvieras en palacio una mujer prudente, y no la peor de todas. Ni aunque quisiera, podría ser casta una de las muchachas espartanas, las cuales, tras abandonar sus casas, tienen carreras y palestras, insoportables para mí, en comunidad

SCRIPTA, Revista internacional de literatura i cultura medieval i moderna, núm. 16 / desembre 2020 / pp. 279-299 
con los jóvenes, con los muslos desnudos y los peplos sueltos. ¿Hay que admirarse, entonces, de que no forméis mujeres castas? Habría que preguntarle eso a Helena, que, abandonando tu hogar, se fue de juerga desde tu palacio con un hombre joven hacia otro país. ¿Y, luego, a causa de ella reuniste un ejército tan numeroso de helenos y los condujiste hacia Ilión? ¿Por la que tú no debiste mover una lanza, escupiéndola al descubrir que era malvada, sino dejar que se quedara allí dando un salario para no recibirla jamás en tu casa? Pero al no alentar tu pensamiento en esa dirección destruiste muchas vidas dignas, dejaste ancianas privadas de sus hijos en sus casas y quitaste sus nobles hijos a padres canosos. Un desgraciado entre esos muchos soy yo. A ti te miro como un espíritu maligno asesino de Aquiles. Tú, el único que regresaste de Troya sin quedar herido siquiera; tus hermosísimas armas en sus hermosos estuches iguales hacia allí y hacia aquí las trajiste. Yo le decía al que se iba a casar que ni anudara lazos de parentesco contigo ni aceptara en su casa la cría de una mala mujer, pues sacan ellas los defectos de sus madres. Considerad eso también, pretendientes: tomad la hija de una buena madre. Además de eso, ¿qué excesos cometiste contra tu hermano, ordenándole que degollara a su hija del modo más estúpido? Tanto temiste no recuperar a tu malvada esposa. Y habiendo tomado Troya — pues iré hasta allí en pos de ti- no mataste a tu mujer al tenerla en tus manos, sino que, en cuanto viste su pecho, arrojando tu espada aceptaste sus besos, acariciando a la perra traidora, porque eres por naturaleza un derrotado por Cipris, oh tú, malvadísimo. Y, después, habiendo venido a casa de mi hijo, tratas de devastarla, mientras él está ausente, y de matar deshonrosamente a una infeliz mujer y a su hijo, el cual te hará llorar a ti y a tu hija que está en el palacio, aunque él fuera tres veces bastardo. Muchas veces, en verdad, un terreno seco supera en grano a otro fértil, y muchos hijos bastardos son mejores que los legítimos. Pero llévate a tu hija. Es más glorioso para los mortales adquirir como suegro y amigo un pobre bueno que uno malvado y rico. Y tú no vales nada. 
Anastasia Terzopoulou. Violencia conyugal y víctimas de la guerra: la valenciana Beatriz Martí y la troyana Andrómaca de Eurípides

1452, marzo, 15. - Barcelona.

Carta de la reina María de Aragón dirigida a mosén Perot Pardo con el fin de que éste cambie de actitud hacia su esposa, doña Beatriz. Marti (ACA, CR, Reg. 3275: ff. 24-25v). ${ }^{37}$

/f. 24/ Per la muller del noble en Perot Pardo.

La Reyna.

Noble e amat nostre. Segurament no poch nos donau causa de maravellar e contra vos ab raho indignar, que nos haver a vos scrit de cosa axi justa e de tanta raho procehint que attes vos haviem haut e havieu indegudament envers la noble e ben amada nostra vostra muller no tractant ni vivint $\mathrm{ab}$ aquella segons ereu tengut vers Deus e lo mon, que per les causes e rahons en les dites letres contengudes haguesseu aquella en altra reputacio. Jatsia vos a les dites nostras letres nos haiau respost, pero no vehem, segons som informada, que los fets se corresponguen ab $/ f .24 v$. / la offerta. Ans, lo que prior es, en loch de condescendre a nostras prechs e les dites nostres letres fer aquella utilitat en aquest negoci que rahonablament deguerem, ara mes que may vos vexau, molestau e donau tal vida a la dita vostra muller que no es en naguna manera de tollerar ni portar ab paciencia. E si asso ha de durar, creheu nos seria forçat per molts respectes emparar nos de la dita noble en tal forma que seria provehit a sa indempnitat e que sera preservada de semblants vexacions e indegut viure.

E vos sabeu be quant haveu la muller bona, honesta e apparentada de tals parents e a nos axi servidors e cosas affixes, que no us sera comportat no sens gran blasme e vergonya vostras e de vostra honor. Car mes val que nos nos hi interposem en semblant manera que no que entre vos e los parents de la dita noble se haguessen a seguir inconvenients e escandols per preservar aquella de tal vida, lo que no podem creure vos vullau meterus en tal punt.

Per que us pregam, encarragam e manam, e encara aconseyllam, que quesvulla que fins açi sia estat vos, daqui avant, per amor e contemplacio nostra e per vostra honor vullau en totes maneres la dita vostra muller tractar e portar e haver en aquella bona reputacio sots tengut e devets segons ley devina e encara lo mon fer. E aço sera cosa que de res a present no'nd poguerets mes complaure. E siau cert que advenint lo cars ho haurem be a memoria e a vos haurem per affectat seruidor.

37 La transcripción de la carta, en García Herrero (2014: 137). 
Anastasia Terzopoulou. Violencia conyugal y víctimas de la guerra: la valenciana Beatriz Martí y la troyana Andrómaca de Eurípides

Encara, per que mills siats informat de les dites coses, havem scrit de nostra intencio sobre aquelles que us diga de nostra part al amat nostra en Johan de Montpalau, donzell de aqueixa Ciutat. Per que donats-li plena fe e crehença, axi com si nos personalment vos lo dehiem, complint-ho per obra segons de vos comfiam. Axi feu que haiam de vos aquella bona resposta e relacio que speram. Data en Barchinona a XV de març del any Mil CCCC LII.

Al noble e amat nostre en Perot Pardo.

Fuit duplicata cum credencia domine Ysabeli Maça. 
Anastasia Terzopoulou. Violencia conyugal y víctimas de la guerra: la valenciana Beatriz Martí y la troyana Andrómaca de Eurípides

1452, marzo, 17. - Barcelona.

Carta de la reina María de Aragón dirigida al doncel don Joan de Montpalau a través de la cual la soberana pedía a su consejero real que interviniera en su nombre sobre el caso de la violencia marital de doña Beatriz. Martí (ACA, CR., Reg. 3275, ff. 25-25v). ${ }^{38}$

Pro eadem

La Reyna.

En Johan de Monpalau. Attes que erem informada que lo noble e amat nostra en Perot Pardo tractava indegudament la noble e amadona (sic) nostra (lac.), muller sua, li scrivim poch ha que per honor sua e contemplacio nostra volgues tractar altrament e portar la dita ça muller ab altra vida, com aquella, per gracia de Deu, sia bona, honesta e ab bon seny. Ell nos respos a les dites nostras letres profferint fer-ho, e ara, segons som informada, en loch de les dites nostras letres haver fet util e aprofitat en aquest negoci e ell condescendre a nostras prechs, ara mes que may, no cessa de donar mala vida a la dita noble, e metre en algun perill axi della com de seguirse entre los parents de la dita dona e lo dit noble scandols e inconvenients per voler preservar aquella de tal vida. E per ço, com la maior part dels dits sos parents, entre los quals ere mossen Johan Ciffre e ara ços fills, e altres familiars de casa nostra, e puix la dita [tachado: culpa] dona no ha culpa ni mereix esser axi tractada, som induhida interposar-nos en aço e provehir a la indempnitat de la dita noble e encara per evitar que los dits inconvenients entre les dites parts nos seguesquen, ara scrivim al dit noble carragant-li la ma como aço es un gran carrech e infamia seus, e que daçi avant se regescha en altra manera, e a la fi de la letra ab crehença a vos acomanada en virtut de la qual vos pregam e encarragam molt affectuosament, axi com aquell qui semblants negocis son be pertinents, tant per esser axi affix ab los parents de la dita noble, quant per esser obra meritoria, que vos en virtut de la dita crehença digau al dit en Perot Pardo tot ço e quant lo feel familiar de casa nostra, n $\square$ Anthon Alamany, lo qual es informat a ple de nostra intençio e voluntat sobre les dites coses, de nostra part vos dira e explicara, enadint-hi per vos mateix tot lo que us sia vist venir be e aprofitar a persuadir lo dit noble a bona concordia e tractament de la dita ça muller. E axi haiau vos hi segons de vos comfiam e lo cars requer.

38 La transcripción de la carta, en García Herrero (2014: 136). 
Anastasia Terzopoulou. Violencia conyugal y víctimas de la guerra: la valenciana Beatriz Martí y la troyana Andrómaca de Eurípides

/f. $25 v$. / E del que fet hi haurets, obtendrets gran merit e a nos singularment complaurets. E haiam de tot vostra resposta. Data en Barchinona a XVII de març del any Mil CCCC Cinquanta dos. La Reyna.

$\mathrm{Al}$ amat nostre en Johan de Monpalau, donzell.

Similis alia fuit expedita a la noble e ben amada nostra dona Ysabel Maça. 
Anastasia Terzopoulou. Violencia conyugal y víctimas de la guerra: la valenciana Beatriz Martí y

la troyana Andrómaca de Eurípides

\author{
Abreviaturas \\ $\mathrm{ACA}=$ Archivo de la Corona de Aragón \\ $\mathrm{CR}=$ Cancillería Real \\ Reg. $=$ Registro \\ $\mathrm{f} .=$ folio \\ $\mathrm{ff} .=$ folios
}

\title{
Fuentes
}

Archivo de la Corona de Aragón (ACA), CR, Reg. 3162, f. 66v.

- ACA, CR, Reg. 3275, ff. 24-25v.

- ACA, CR., Reg. 3275, ff. 25-25v.

- ACA, CR, Reg. 3275, f. 59v.

Archivo del Reino de Valencia, Maestre Racional, no 472, f. 6v.

Aristóteles (1992): Investigación sobre los animales (introducción de García Gual, C.; traducción y notas de Palli Bonet, J.), Madrid, Editorial Gredos.

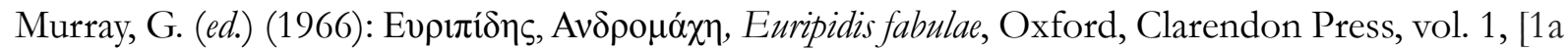
ed. 1902].

Higino (2009): Fábulas, Del Hoyo, J. \& García Ruír, J. M. (introd. y trad.), Madrid, Editorial Gredos.

Euripides (1920): Andromache, Kovacs, D. (ed.), Cambridge, Harvard University Press, Perseus Digital Library. Recuperado de: http://www.perseus.tufts.edu/hopper/text?doc=Perseus $\% 3$ Atext $\% 3 \mathrm{~A}$ 1999.01.0089\%3Acard\%3D693 (16 de octubre de 2020).

Eurípides (1990-1998): Tragedias. Obra completa, El Cíclope. Alcestis. Medea. Los Heraclidas. Hipólito. Andrómaca. Hécuba, Medina González, A. / López Férez, J. (eds.), Madrid, Editorial Gredos, vol. 1. [1990, $1^{\text {a }}$ edición, $5^{\mathrm{a}}$ impresión].

Jenofonte / Pseudo Jenofonte (1984): Obras menores. Hierón. Agelisao: la República de los Lacedemonios. Los ingresos públicos. El jefe de la caballería. De la equitación. De la caza / La República de los Atenienses (introducciones, traducciones y notas de Guntiñas Tuñón, O.), Madrid, Editorial Gredos.

Marco Tulio Cicerón (2008): Disputas tusculanas, 2a . ed., (introd., versión y notas de Pimentel Álvarez, J.), México, UNAM/IIFL.

Plutarco (1985): Vidas Paralelas. Obra completa. Volumen I: Teseo \& Rómulo; Licurgo \& Numa, Madrid, Editorial Gredos. 
Anastasia Terzopoulou. Violencia conyugal y víctimas de la guerra: la valenciana Beatriz Martí y la troyana Andrómaca de Eurípides

\section{Bibliografía}

Burgess, J. (1995): «Achilles heel: the death of Achilles in ancient myth». Classical Antiquity, 14 (2), 217. DOI $10.2307 / 25011021$.

Bernabé, A. (1979): Fragmentos de épica griega arcaica, Madrid, Gredos.

Earenfight, T. (2010): The king's other body: Maria of Castile and the crown of Aragon. Philadelphia, University of Pennsylvania Press.

Echevarría, A. (2002): Catalina de Lancaster. Reina Regente de Castilla (1372-1418), Hondarribia, Nerea.

Fossier, R. (1996): La Sociedad Medieval, Madrid, Ed. Taurus.

García Herrero, M. C. (2014) «Solidaridad femenina ante el maltrato marital a finales de la Edad Media. Algunas intervenciones de la reina de Aragón», García Herrero, M. C. \& Pérez Galán, C. (coords.), Mizjeres de la Edad Media: actividades políticas, socioeconómicas y culturales, Zaragoza, Institución “Fernando el Católico”, pp. 136-137.

Grimal, P. (1951; ed. de 1989): Diccionario de mitología griega y romana, Barcelona, Paidós.

Hose, M. (2008): Euripides. Der Dichter der Leidenschaften, Munich, C. H. Beck, p. 80.

Perseus Digital Library. Gregory R. Crane (ed.). Tufts University. http://www.perseus.tufts.edu (16/10/2020).

Pomeroy, S. B. (1991): Diosas, rameras, esposas y esclavas: Mujeres en la Antigüedad clásica, Madrid, Ediciones Akal, pp. 109-110.

. (1977): «Technikai kai mousikai: The education of women in the fourth century and in the Hellenistic period». American Journal of Ancient History, 2, pp. 51-68.

Ramírez Almazán, D., Martín Clavijo, M., Aguilar González, J. \& Cerrato, D. (2011): La querella de las mujeres en Europa e Hispanoamérica, Sevilla, Arcibel Editores.

Ryder, A. (1992): Alfonso el Magnánimo, rey de Aragón, Nápoles y Sicilia (1396-1458), Valencia, IAM.

Sáiz Serrano, J. (2008): Caballeros del rey. Nobleza y guerra en el reinado de Alfonso el Magnánimo, Valencia, Universitat de València, p. 317.

Soldevila, F. (1928): «La Reyna Maria muller del Magnànim Sobiranes de Catalunya», Barcelona, Real Academia de Buenas Letras de Barcelona, pp. 213-345.

Vidal, J. J. (1991): Mallorca en tiempos del descubrimiento de América, Palma de Mallorca, El Tall.

. (2007): «Mallorca en la segunda mitad del siglo XV. Panorama socioeconómico», Medicina Balear, pp. 22-32.

Wikimedia Commons. «Andrómaca cautiva», Pintura. [Fig. 2]. Recuperado de: <https://commons. wikimedia.org/wiki/File:Marie_Kastilie.jpg].

. «María de Castilla, reina de Aragón». Detalle de ilustración. [Fig. 3.]. Recuperado de: $<$ https:/ / commons.wikimedia.org/wiki/File:Marie_Kastilie.jpg].

SCRIPTA, Revista internacional de literatura i cultura medieval i moderna, núm. 16 / desembre 2020 / pp. 279-299 